Infusionsther Transfusionsmed 1993;20(suppl 2):1

\title{
Entwicklungen in der Transfusionsmedizin
}

Infektionen Virusinaktivierung Autologe Bluttransfusion Immunhämatologie 35. Jahrestagung der Gast-Herausgeber:

Arbeitsgemeinschaft der Ärzte A. Poschmann, Hamburg

staatlicher und kommunaler Bluttransfusionsdienste e. V.

Hamburg, 11. bis 13. Juni 1992

KARGEK 